\title{
Aeroacoustic Noise Analysis of Automobile Air Conditioning System
}

\author{
Ming $\mathrm{Li}^{1, \mathrm{a}}$, Liyu Guo ${ }^{2, \mathrm{~b}}$ Qin Guo ${ }^{3, \mathrm{c}}$ \\ ${ }^{1}$ Jilin University, Changchun, Jilin Province 130022, China. \\ ${ }^{2}$ Zhuhai college of Jilin University,Zhuhai, Guangdong Province 541009, China. Corresponding \\ author. \\ ${ }^{3}$ School of Management Science and Information Engineering, Jilin University of Finance and \\ Economics, Changchun, Jilin Province 130117, China
}

aemail: limingtiger@163.com , bemail:20547284@qq.com , cemail: 375716125@qq.com

\begin{abstract}
Keywords: HVAC System, Aeroacoustic Noise, CFD, Experiment
Abstract:Acoustic noise of air conditioner is one of the main vehicle interior noises. In this paper, the value of the acoustic noise obtained under specific rotational velocities that tested in the experiment has been analyzed and the distribution of the noise with the analysis of the sound field in the HVAC System (heating ventilation and air-conditioning) also has been achieved. A spectrum analysis of outlet noise was used for comparison of variable noise source characteristics. As soon as the HVAC System modeling and simulation completed in the CDF software, it had laid emphasis to analyze the influence of the inner structures of HVAC System on the acoustic noise and two comparisons were made, one between the simulation and the experiment, the other one between the integrated HVAC system and the simplified in the simulation. Good agreement was achieved between simulation and experiment results.
\end{abstract}

\section{Introduction}

As time goes on and thanks to greater access to the vehicle, greater attention is patched to the vehicle noise, which is one of the principal elements about automobile comfort. The main thesis about this paper is that the HVAC System's acoustic noise. Reasonable structure design, especially the air duct will improve the acoustic noise of HVAC System remarkably. Scholars have carried numerical researches on $\mathrm{it}^{[1-4]}$. Dongkon Lee ${ }^{[2]}$ has studied the impact of air outlet grille on the aero-acoustic noise, indicating that at the range of $200-3000 \mathrm{HZ}$, the noise is main produced by the HVAC System, and angle of air outlet grille influence both the flow-rate distribution and acoustic noise producing. Stéphane Détry ${ }^{[3]}$ has estimated turbulence noise with studying the channel outlet on vehicle dashboard by numerical simulation. The comparison between the simulation and the experiment demonstrates that the simulation can meet the industrial requirements. Besides, Mayur $\mathrm{Sah}^{[4]}$ has made a prediction of the HVAC System generation and propagation using CFD, and got the conclusion that the overall sound pressure level at a near field cabin location is obedient with the test results. Vasanth,B. ${ }^{[5]}$ has carried out a 3D computational analysis method to predict the noise originated from HVAC unit with an error with $10 \%$ between simulation and test results. This paper targets an A-class vehicle air conditioner of a relevant brand in market, which was simulated and modeled based on CFD software. To analyze the influence of the inner structures of HVAC System on the acoustic noise, two comparisons were made, one was between the simulation and the experiment, and the other was between the integrated HVAC system and the simplified model in the simulation. 


\section{HVAC System}

HVAC System mainly consists of evaporator, blower, ventilation door, heater and air filter. The fresh air, that is blew in the system by the blower, proceeds in the evaporator and is regulated by the ventilation door at a specific angle to achieve air distribution. The vehicle air conditioner includes three modes, i.e. defroster, dashboard, foot-well. Normally, dashboard mode has serious noise problem, so dashboard mode is the principal subject in this paper. The structure of the HVAC System is shown in Fig.1. The air filter, evaporator and heater will be dealt as porous material in the simulation.

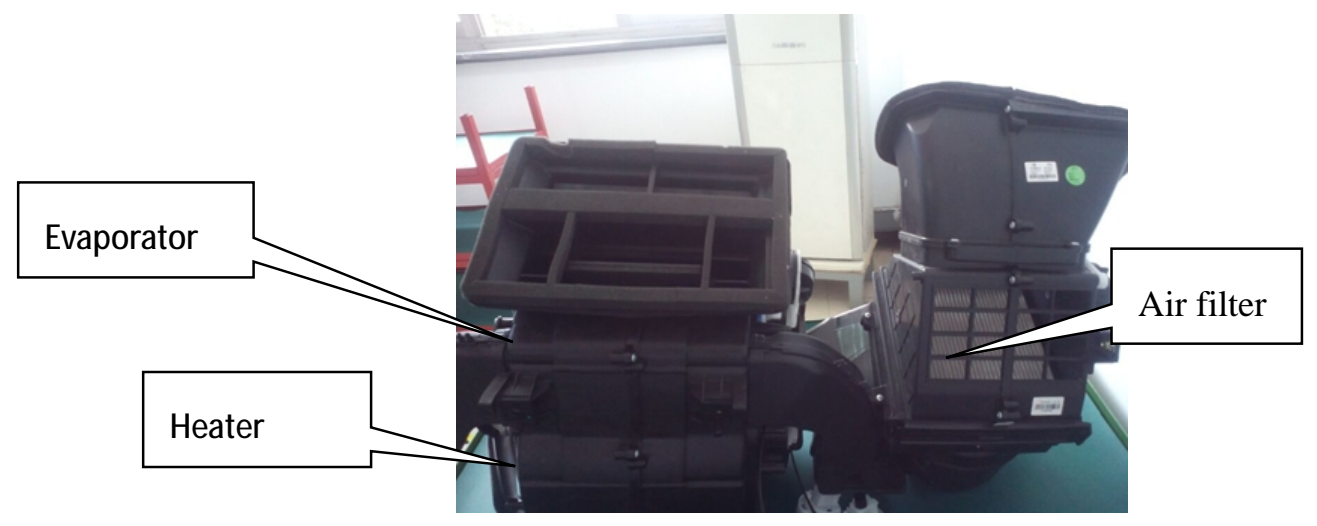

Fig.1 HVAC system

\section{Experiment setup}

The system was tested in a semi-anechoic room to ensure that the noise from HVAC System would be tested accurately. The instruments and devices employed in this experiment contains Maynuo m8811 DC power, which is programmable and has a max voltage value of $30 \mathrm{~V}$ and max current value of 5A, a B\&K PULSE 3560B dot analyzer is used for noise spectrum analysis, and a Hall sensor is used for collecting the information of the blower's rotate speed, and a microphone whose brand is LEWWITT_LCT240, with a high sensitivity is used to test the noise.

The system was tested at the voltage $6 \mathrm{~V}, 9 \mathrm{~V}$ and $12 \mathrm{~V}$ separately. In all three cases, unnecessary factors that may produce negative influences on the precision of the experiment must be eliminated, for example, that the HVAC System instruments used must be of high quality and excellent performance. Furthermore, the stability must be ensured to avert the vibration between the HVAC System and test bench, the device is shown in Fig.2.

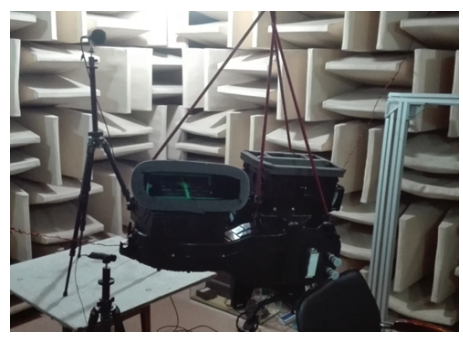

a) The noise analysis of outlet

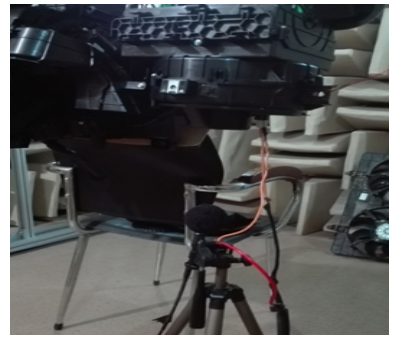

b) The blower order analysis

Fig.2 The noise experiment setup

\section{Experimental results analysis}

The signals was obtained in such conditions that different rotate rates corresponding to the voltage value at $6 \mathrm{~V}, 9 \mathrm{~V}$ and $12 \mathrm{~V}$ separately analyzed with the $\mathrm{B} \& \mathrm{~K}$ software, and the noise cascade is 
shown in Fig.3.(a). As a fast Fourier transform of the sound pressure was taken, the noise frequency spectrum behavior at sound order 12,24,36,48 and overall spectrum about blower was obtained. When the value of overall noise spectrum decreases by $10 \mathrm{~dB}(\mathrm{~A})$, the PLF noise spectrum behavior emerges. As shown in Fig.3.(b), it indicates that the noise frequency spectrum at order of 12, 24, 36, 48 are wholly under the PLF spectrum, which means the blower meets the test requirements.
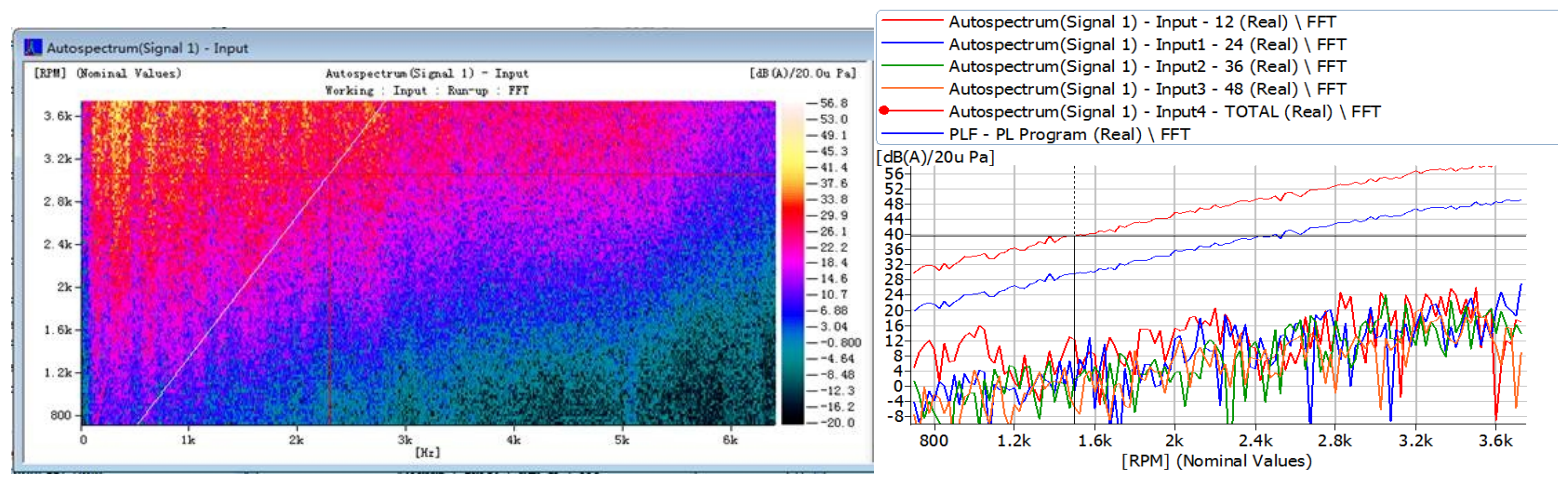

a) The sound cascade

b) The noise frequency spectrum

Fig. 3 The sound order of blower

The noise frequency spectrum behavior of blower is shown in Fig.4. In Fig.4(a), the rotation noise of blower is remarkable, which can be observed clearly, and the peak value exists at both basic frequency and frequency multiplication, and decreases as frequency increases. Taking a treatment of sound pressure at every $1 / 3$ noise frequency multiplication in Fig.4.(b) can get the overall sound pressure of blower.

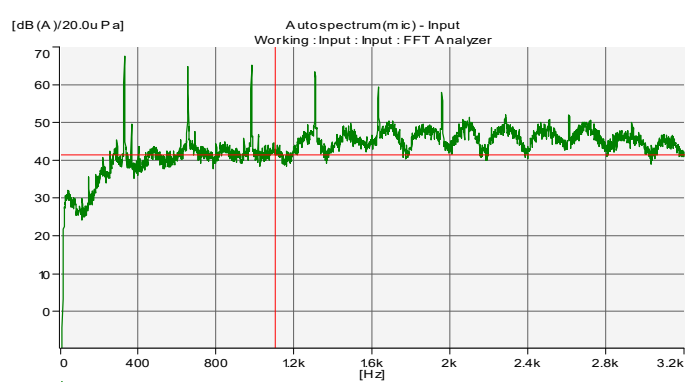

a) FFT analyzing

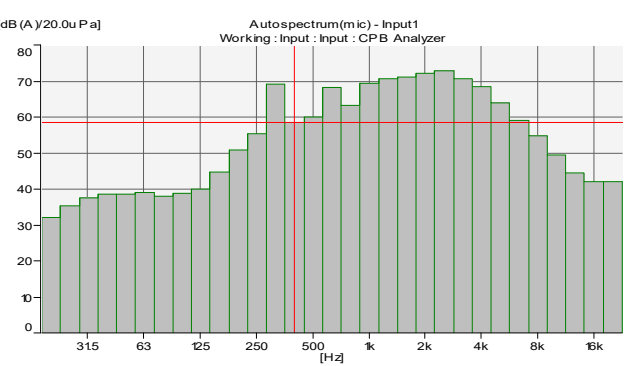

b) CPB analyzing

Fig.4 The noise frequency spectrum behavior of blower

Fig.5 is the noise frequency spectrum behavior of air conditioner outlet. Fig.5.(a) indicates that there exists no peak values and the noise value decreases as the frequency increases, and it is a typical broad band noise. Taking a treatment of sound pressure at every $1 / 3$ noise frequency multiplication in Fig.5.(b) can get the overall sound pressure of outlet.

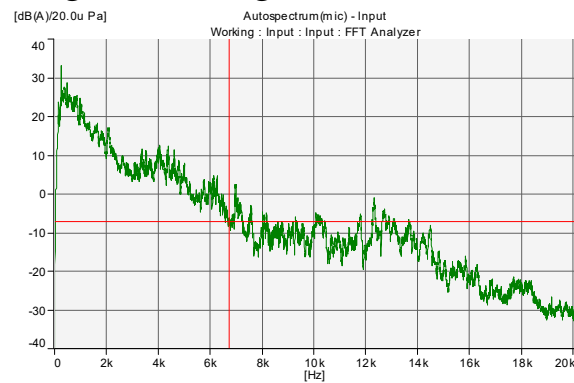

a) FFT analyzing

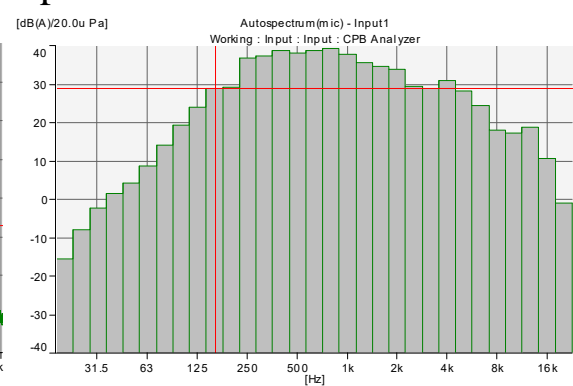

b) CPB analyzing

Fig.5 The noise frequency spectrum behavior of outlet.

The overall noise behaviors of the HVAC System are analyzed under separate rotate rates of the blower regulated by voltage set as $6 \mathrm{~V}, 9 \mathrm{~V}, 12 \mathrm{~V}$. That is shown in Table1. 
Table1 The test results under certain operating conditions

\begin{tabular}{ccccc}
\hline Voltage(v) & $\begin{array}{c}\text { Static } \\
\text { pressure }(\mathrm{Pa})\end{array}$ & Rotate rate(rpm) & Overall pressure level(dB(A)) \\
& & & outlet & blower \\
\hline 6 & 0 & 2075 & 60.5 & 65.4 \\
9 & 0 & 3006 & 70.1 & 75.6 \\
12 & 0 & 3741 & 71.1 & 77.6 \\
\hline
\end{tabular}

It is found that the value of noise from blower is higher than outlet under the same rotate rate, and they both increase as the rotate rate increases. However, the blower noise exerts much less negative impact on passengers indoor than outlet because the layout of blower is remote from the capsule, which determines a faint effect even ignored, on the outlet. Passengers will percept the noise, which has an intimate connection with the air duct configuration of the HVAC System, from the outlet.

The simulation analysis of HVAC System

\section{Simulation model}

It is so important for the HVAC System to perform regularly with the devices as evaporator, heater and air-filter, which are so complicated that they generate giant numbers of meshes, usually with poor quality, and may produce great extra calculations in the CFD simulation. The precision of the result is suspected as well. Considering the features of the three configurations, they can be dealt with equivalently of porous media which are anisotropic. The final HVAC System model in CFD software is shown in Fig.6.

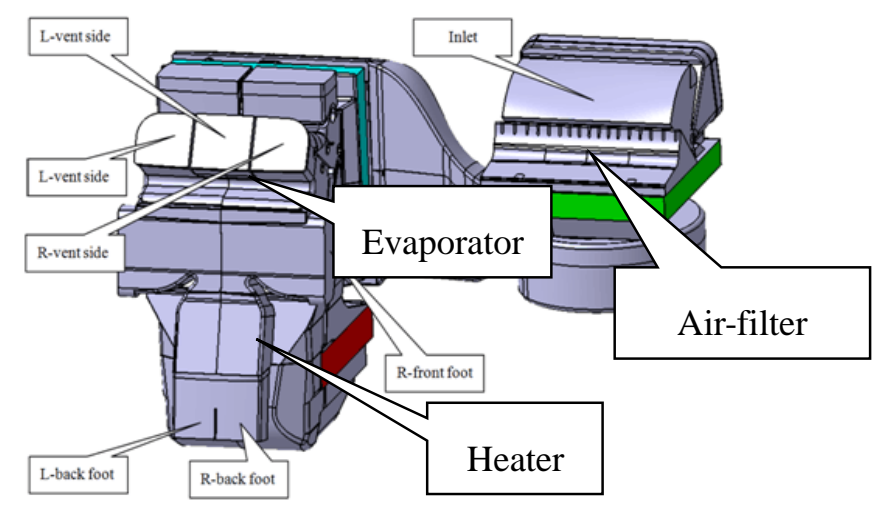

Fig.6 The final model of the HVAC System in CFD simulation

\section{Mesh generation}

The volume mesh adopted in this paper is polyhedral mesh, and the mesh generated on the surface of blower's blades, inlet, outlet, air dust and the interfaces are required more dense and diminutive. To weaken the impact of the reflux, a stretching treatment for outlet mesh is essential. In order to investigate how much influence the boundary layer attaches on the calculation, a prism mesh generation is needed. The final number of mesh generation in HVAC System is 4850000 , as shown in Fig.7. 


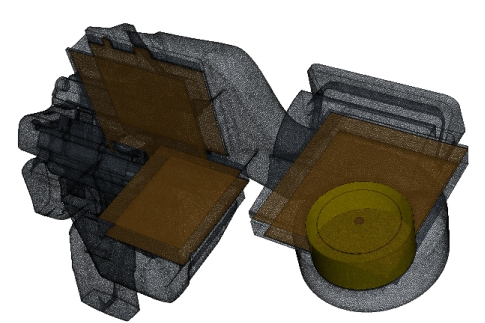

Fig.7 The volume mesh of the HVAC System

The turbulent model

The flow field model

The viscosity of low Reynolds number flow has been taken into consideration in RNG k-e model, that entitles it a high precision and rapid convergence. The mode chosen under stable state calculation in CFD analysis is Realized k-e, whose basic governing equations show as Eq.(1) and Eq.(2).

$$
\begin{gathered}
\frac{d}{d t} \int_{V} \rho k d V+\int_{A} \rho k\left(\stackrel{r}{v}-\stackrel{r}{v}_{g}\right) \cdot d a= \\
\int_{A}\left(\mu+\frac{\mu_{t}}{\sigma_{k}}\right) \nabla k \cdot d \stackrel{r}{a}+\int_{V} f_{c}\left[G_{k}+G_{b}-\rho\left(\left(\varepsilon-\varepsilon_{0}\right)+\gamma_{M}\right)+S_{k}\right] d V \\
\frac{d}{d t} \int_{V} \rho \varepsilon d V+\int_{A} \rho \varepsilon\left(\stackrel{r}{v}-\stackrel{r}{g}_{g}\right) \cdot d a= \\
\int_{A}\left(\mu+\frac{\mu_{t}}{\sigma_{\varepsilon}}\right) \nabla \varepsilon \cdot d a+\int_{V}^{r}\left[C_{\varepsilon 1} S \varepsilon+\frac{\varepsilon}{k}\left(C_{\varepsilon 1} C_{\varepsilon 3} G_{b}\right)-\frac{\varepsilon}{k+\sqrt{v \varepsilon}} C_{\varepsilon 2} \rho\left(\varepsilon-\varepsilon_{0}\right)+S_{\varepsilon}\right] d V
\end{gathered}
$$

Where $S_{k}, S_{\varepsilon}$ are source items with the unit $\mathrm{W} / \mathrm{m}^{3} . \varepsilon_{0}$ is the value of ambient turbulence with the unit $\mathrm{J} / \mathrm{kg}$. $\mathrm{f}_{\mathrm{c}}$ is the curvature correction factor. $\gamma_{\mathrm{M}}$ is the dissipative extension with the unit $\mathrm{m}^{2} / \mathrm{s}^{3} \cdot \mathrm{S}$ is the parameter of strain rate $\mu$ is the dynamic viscosity, $\mu_{t}$ is the turbulent viscosity with the unit $\mathrm{m}^{2} / \mathrm{s}$. $G_{\mathrm{b}}, G_{k}$ are the produce of turbulence with the unit $\mathrm{J} / \mathrm{kg} . C_{\varepsilon 1}, C_{\varepsilon 2}$ and $C_{\varepsilon 3}$ are the coefficient with the values as 1.44,1.9,0.09 respectively. $\sigma_{\mathrm{k}}, \sigma_{\varepsilon}$ are both Schmidt number with the values as 1.0 and 1.2. The instability calculation model chosen in CFD analysis is the DES based on two equations, that are shown as Eq.(3) and Eq.(4), of the Menter k-w SST.

$$
\begin{gathered}
\frac{D(\rho k)}{D t}=\tau_{i j} \frac{\partial u_{i}}{\partial x_{j}}-\beta^{*} \rho \omega k+\frac{\partial}{\partial x_{j}}\left[\left(\mu+\sigma_{k} \mu_{t}\right) \frac{\partial k}{\partial x_{j}}\right] \\
\frac{D(\rho \omega)}{D t}=\frac{\gamma}{v_{t}} \tau_{i j} \frac{\partial u_{i}}{\partial x_{j}}-\beta \rho \omega^{2}+\frac{\partial}{\partial x_{j}}\left[\left(\mu+\sigma_{\omega} \mu_{t}\right) \frac{\partial \omega}{\partial x_{j}}\right]+2 \rho\left(1-F_{1}\right) \sigma_{\omega 2} \frac{1}{\omega} \frac{\partial k}{\partial x_{j}} \frac{\partial \omega}{\partial x_{j}} \ldots
\end{gathered}
$$

Where $\beta$ is the coefficient of thermal expansion, $\beta^{*}$ is the reference coefficient of thermal expansion with the value 0.09 . F1 is the blending coefficient, when near the wall $F 1=1$, but far from the wall 
F1 $=0 . \sigma_{\mathrm{k}}, \sigma_{\varepsilon}$ are both Schmidt number. $\mu$ is the dynamic viscosity, $\mu_{\mathrm{t}}$ is the turbulent viscosity both with the unit $\mathrm{m}^{2} / \mathrm{s}$.

It has an enormous influence for the time on the step length in CFD calculation. The equation used here is shown in Eq.(5).

$$
\Delta t=\frac{60}{n z k}
$$

Where $\mathrm{n}$ is the rotate rate with the unit rpm, $\mathrm{z}$ is the number of the blower blades, $\mathrm{k}$ is iterations.

The boundary condition

In the CFD analysis, the boundary conditions should be set. The Table2 lists the boundary conditions in the CFD simulation with the wall treatment mode of "All y+" and the rotate rate in harmony with the test.

Table 2 the boundary conditions in the simulation

\begin{tabular}{lccc}
\hline Boundary condition & foot door & foot door & foot door \\
\hline Inlet condition & stagnation & stagnation & stagnation \\
Outlet condition & pressure outlet & pressure outlet & pressure outlet \\
& $0 \mathrm{~Pa}$ & $0 \mathrm{~Pa}$ & $0 \mathrm{~Pa}$ \\
Rotate rate of the blower & $2075 \mathrm{rpm}$ & $3006 \mathrm{rpm}$ & $3741 \mathrm{rpm}$ \\
\hline
\end{tabular}

\section{The result comparison between the test and simulation}

As shown in Table3, it suggests that the simulation meets the requirement with the error of $3 \%$, demonstrating that the model of turbulence and acoustics chosen here is correctly.

Table 3 the comparison between the text and simulation in the specific operating conditions Operating model Rotate rate(rpm) Overall sound pressure(dB(A)) Error

\begin{tabular}{ccccc} 
& & test & simulation & $\%$ \\
\hline 1 & 2075 & 60.5 & 59.12 & 2.28 \\
2 & 3006 & 70.1 & 68.3 & 2.57 \\
3 & 3741 & 72.1 & 70.6 & 2.08 \\
\hline
\end{tabular}

The comparison between the integrated HVAC System and the simplified in the simulation It is necessary that investigating the HVAC System with and without the evaporator, heater and air filter to distinguish the influences of the three configurations on the distribution of sound field. The Fig. 8 shows basic frequency spectrum Fig.8(a) and $3^{\text {rd }}$ octave frequency spectrum Fig.8(b) of sound pressure that has taken the blades, surface of the duct configuration and the air outlet as the source in the integrated HVAC System (with the evaporator, heater and air-filter). By comparison, it indicates that the spectrum graph of the sound pressure contains no remarkable peak values when the source is the duct surface. But when the blade is taken as the source, it indicates that the peak values obviously exist at $1500 \mathrm{HZ}, 3000 \mathrm{HZ}$ and $4500 \mathrm{HZ}$, indicating that the rotation noise attenuates to turbulence noise under the HVAC System regulation. 


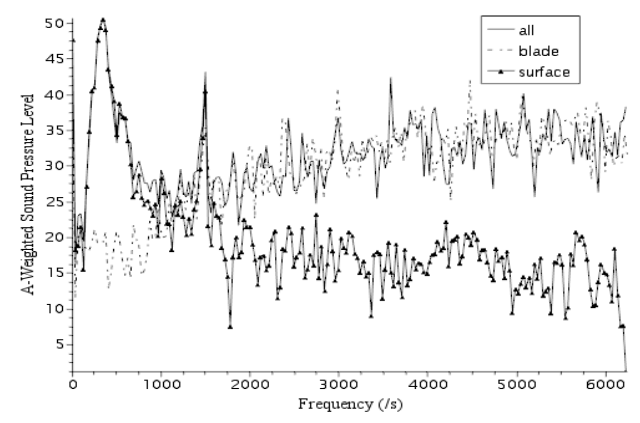

a) basic frequency spectrum

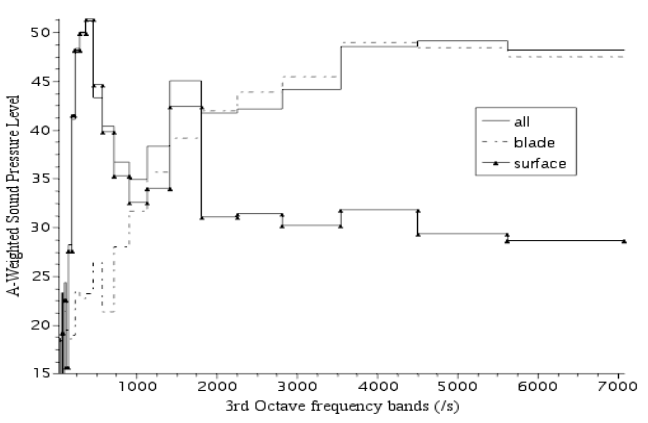

b) $3^{\text {rd }}$ octave frequency spectrum

Fig. 8 the spectrum graph of the noise soure in HVAC System without evaporator air filter and heater The Fig.9 shows basic frequency spectrum Fig.9(a) and $3^{\text {rd }}$ octave frequency spectrum Fig.9(b) of the sound pressure that has taken the blades, surface of the duct configuration and the air outlet as the source in the simplified HVAC System(without the evaporator, heater and air filter) .By comparison, it indicates that the spectrum graph of the sound pressure contains no remarkable peak values when the source is the duct surface .But when the blades is taken as the source, it indicates that the peak values obviously exists at $1500 \mathrm{HZ}, 3000 \mathrm{HZ}$ and $4500 \mathrm{HZ}$, especially, the basic frequency of sound pressure level is $40.06 \mathrm{~dB}(\mathrm{~A})$, indicating that the rotation noise attenuates to turbulence noise under the HVAC System regulation as well.

Comparing Fig.8 with Fig.9, it indicates that the spectrum graphs of the sound pressure have greatly consistency, but minor margins. When the source is the blade, it is $5.17 \mathrm{~dB}(\mathrm{~A})$ higher in the integrated HVAC System than the simplified.
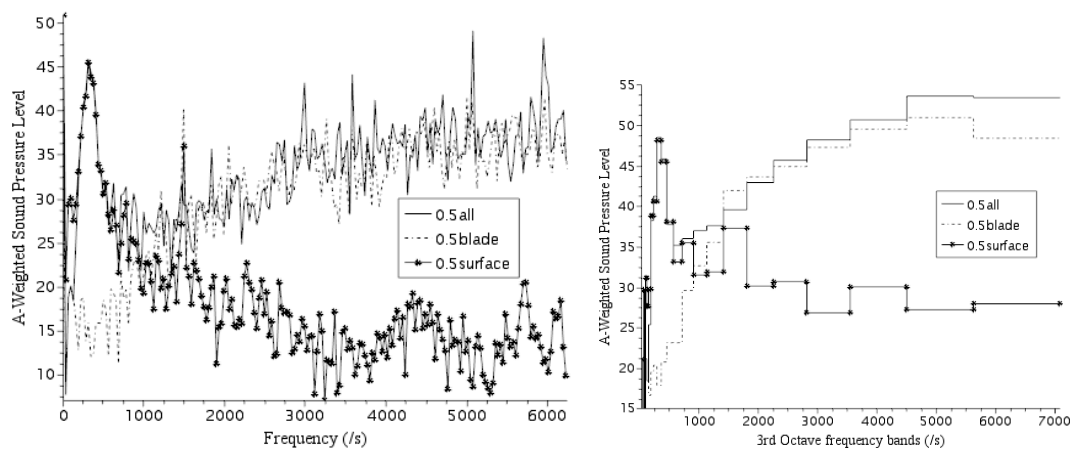

a) basic frequency spectrum

b) $3^{\text {rd }}$ octave frequency spectrum

Fig.9 the spectrum graph of the noise soure in HVAC System with evaporator air filter and heater As shown in the Table4, when taking the duct surface and blade as the source respectively, it is $0.36 \mathrm{~dB}(\mathrm{~A})$ and $1.49 \mathrm{~dB}(\mathrm{~A})$ higher in the integrated HVAC System than the simplified model.The reason of this phenomenon is that when the disturbance, velocity gradient and static pressure gradient increases, the flow field deteriorates which leads a higher energy lost. It increases the noise when the system starts up .

Table4 The comparison of overall sound pressure with different noise source

\begin{tabular}{cccc}
\hline Noise source & $\begin{array}{c}\text { Integrated HVAC System } \\
(\mathrm{dB}(\mathrm{A}))\end{array}$ & $\begin{array}{c}\text { Simplified HVAC System } \\
(\mathrm{dB}(\mathrm{A}))\end{array}$ & $\begin{array}{c}\text { Margin } \\
(\mathrm{dB}(\mathrm{A}))\end{array}$ \\
\hline Duct & 51.35 & 51.71 & 0.36 \\
Blade & 54.68 & 56.17 & 1.49 \\
All & 59.12 & 60.28 & 1.16 \\
\hline
\end{tabular}




\section{Conclusions}

This paper targets an A-class vehicle air conditioner of a relevant brand in market, which is simulated and modeled in CFD software later. It emphasizes on analyzing the influence on acoustic noise by the inner structures of HVAC System, and makes comparison with the experiments. The results indicate:

1.tthe overall sound pressure of the outlet, that is $60.5 \mathrm{db}(\mathrm{A}), 70.1 \mathrm{db}(\mathrm{A}), 72.1 \mathrm{db}(\mathrm{A})$ respectively, under the rotate rate of $2075 \mathrm{rpm}, 3006 \mathrm{rpm}, 3741 \mathrm{rpm}$.

2. the overall sound pressure of the outlet, that is $59.12,68.3 \mathrm{db}(\mathrm{A}), 70.6 \mathrm{db}(\mathrm{A})$ respectively, under the rotate rate of $2075 \mathrm{rpm}, 3006 \mathrm{rpm}, 3741 \mathrm{rpm}$. And comparing to the experiment, there exists errors of $2.28 \%, 2.57 \%, 2.08 \%$ respectively.

3. By the comparison, the spectrum graphs of the sound pressure have greatly consistency, but a minor margin. When the source is the blade, it is $5.17 \mathrm{~dB}(\mathrm{~A})$ higher in integrated HVAC System than the simplified. When taking the duct surface and blade as the source respectively, it is $0.36 \mathrm{~dB}(\mathrm{~A})$ and $1.49 \mathrm{~dB}(\mathrm{~A})$ higher in the integrated HVAC System than the simplified.

So from the simulation of the HVAC System in CFD simulation, compared with the test result, the simulation result both in the velocity field and the acoustic noice field is consistent with the experiment. The result is acceptable. CFD can use in the design of the air duct and HVAC system optimization, improve the work efficiency.

\section{Competing Interests}

The authors declare that they have no competing interests.

\section{Acknowledgements}

This work was financially supported by the Premier-Discipline Enhancement Scheme Supported by Zhuhai Government Fund.

\section{References}

[1] Junwei hu. Study on acoustic characteristics of the aerodynamic noise and air conditioner duct system[D]. Shanghai Jiao Tong University, 2006

[2] Dongkon Lee, Myung Han Lee, Kang-Duck Ih and Moo-Sang Kim. Aero-acoustics Predictions of Automotive HVAC systems[C]. SAE paper, 2010-01-0415, 2010

[3] Stéphane Détry, Julien Manera, Yves Detandt and Diego d'Udekem. Aero-acoustic Predictions of Industrial Dashboard HVAC system[J]. Noise Control Engineering Journal. 2011, 59(2): 177-185

[4]Mayur Sah and Kumar Srinivasan Chrysler Group LLC. Prediction of HVAC System Aero/Acoustic Noise Generation and Propagation using CFD. SAE paper 2013-01-0856

[5]Vasanth,B., Sathish,K., and Sah,M. Studies on Aero-Acoustic Noise Prediction of MAC Unit Using Computational Modelling. SAE Technical Paper 2016-01-0218

[6] Fujun wang. The Analysis of Computational Fluid Dynamics[M].Peking: Tsinghua University Press, 2004

[7] Florian R. Menter. Zonal Two Equation k-w Turbulence Models for Aerodynamic Flows[C]. AIAA paper-93-2906, 1993 